\title{
Family Play-Learning: Some Learning Outcomes from Make-and-play Activities with Toys at a Science Museum
}

\author{
Peeranut Kanhadilok, Mike Watts \\ Department of Education, Brunel University London, UK
}

\begin{abstract}
This paper describes an initial attempt to chart family play-learning outcomes from make-and-play activities with traditional Thai toys. Family learning is a component of inter-generational learning, and we explore this through 'edutainment' activities within the informal educational system of a science museum. The study follows 55 families, including children, teenagers and adults, a total of 125 participants. We use a Toy Learning Outcomes Questionnaire (TLOQ) to study families' learning outcomes from the traditional Thai toy activities at the National Science Museum, Thailand. TLOQ uses a four-point Likert-style scale to explore seven areas of interest: (i) knowledge and understanding; (ii) skills; (iii) attitudes and values; (vi) enjoyment, inspiration and creativity; (v) action, behaviour and progression; (vi) science learning, and (vii) attitude towards local Thai wisdom. Our agenda has been to detail these key areas of concern before discussing the fieldwork we have conducted at the National Science Museum, Thailand, after which we then draw summary conclusions.
\end{abstract}

\section{Introduction}

This paper presents some preliminary results from family play-learning through make-and-play activities with the traditional Thai toys at a science museum. The research has several strands and will be reported in full in due course. Our intention has been to create a 'play-learning-zone' within the Traditional Thai Technology gallery of Thailand's National Science Museum, as a means of using toys to teach science. The museum opened to the public in 2000, and has a dual mission: (i) to develop both 'Western' scientific literacy, and (ii) the traditional local cultural wisdom of Thai society. Its purpose is to foster awareness in its visitors of the importance of science and technology in everyday life, and in the sustainable development of the country through community understanding.

In general, science museums are sites of informal education for visitors all of ages, designed to generate understanding of recent and contemporary science. The Thai Traditional Technology gallery is one of six in the museum, in this case designed specifically to inspire learning about the relationship between Western scientific knowledge and local
Thai wisdom. The gallery has deliberately invoked a sense of play through the use of toy-making activities, looking to foster children and adults' engagement in science learning through make-andplay activities with traditional, locally made, toys. Our on-going research seeks to evaluate the quality of engagement with these toys, and assess the learning outcomes that ensue from these play activities provided for both child and adult visitors to the museum. This agenda leads us to explore an assessment instrument called the Toy Learning Outcome Questionnaire (TLOQ). Participants in the toy-making activities are family groups from within the general public, day visitors to the museum, who volunteer to join the activities and respond to the TLOQ. As volunteers, they represent all age groups, and have varied levels of educational achievement and backgrounds in science.

\section{Family learning in science museums}

The main purpose of families visiting a museum is to have an enjoyable learning experience, garnering new experiences and insights together. In the context of this paper, family learning encompasses members of a family engaging and interacting together in a museum rather than, say, splitting up and going their own separate ways once inside the building. Families commonly use museums as socially mediated meaning-making environments. In other words, families use museums as a good setting to learn together - few visitors indeed arrive at a museum with the feeling they have nothing at all to learn from the visit. In actuality, they spend the majority of their time in conversation, sharing what they know and trying to discover and construct further knowledge together Falk and Dierking, [14]. Cooper [10] points out that families visit museums to seek both pleasure and enjoyment from their visit, alongside a need for the visit to be an informative and educational experience. Wood [27] has stated that '...the attitude that museums are "good place" to take children, and the fact that the largest postulated visiting group comprises families' (p.20) is one reason for the enduring appeal of museums as places of education and entertainment.

The term 'family group' is used to describe multigenerational groups, with one or more adult accompanying either a single child or several children. In our experience, family groups commonly 
comprise a mix of ages and abilities, from grandparents to 'babes in arms', from non-qualified to post-university achievement. A usual group might be formed of one or two parents, a teenager and one or two primary-aged children, possibly with members of the extended family, such as cousins, neighbours or friends. Family groups constitute the largest percentage of visitors to most museums, in general about $60-70 \%$ of those arriving through the doors [14], and comprise the largest 'group numbers', second only to school tours.

A study at the Children's Discovery Museum, USA, underscores the important role that parents play in helping their children to select and identify appropriate details in the exhibition and activities. Engaging with their parents in this way, the children reported that they viewed the exhibition with more 'perceptive eyes' [26]. That study focused on a comparison between children who explored the exhibition with parents or on their own, and 'parentally-guided' children were shown to undertake longer and broader explorations of exhibits. In this way, parents supplemented the museum's own resources to become aids in facilitating their children's learning through providing good lead-in questions, supporting and guiding within the activities. Museums help children not only to gain confidence in themselves as capable learners, but also encourage them to develop relationship with adults in the family and support adults (parents and grandparents) as effective teachers of children [9].

Adult visitors enjoy learning in the museum in parallel with teaching or introducing knowledge to their children. In this context, learning occurs when families participate in the exhibitions and activities, when parents and adult in the family group learn themselves, and encourage children's learning through asking and answering the questions, talking about the exhibits, pointing to the section of the exhibits, reading text and engaging in hand on activities. Borun, Chambers and Cleghorn [19] have stated

"Family groups that visit a museum can enrich its culture, storing knowledge for later sharing among family members. We can think of this as "potential learning” by analogy to potential energy. If information and association are acquired by a member of the group, they are available for exchange with other family members, not just at the moment of acquisition, but at any time in the future' (p.125).

\section{Family play-learning and science museums}

Family learning itself provokes wide-ranging discussion. Those who seek to promote family learning acknowledge the central role of the family in a child's learning, validating the nature of that learning by engaging families in dialogue about learning, and facilitate the participation of families in the design and enjoyment of learning. It has been described as parents and children learning together; parents learning more about how their children learn; parents taking up learning opportunities to benefit their own learning, including literacy and numeracy, parenting courses, or other courses which interest them; learning with siblings, grandparents, step family and close family friends, and - in some instances - adults learning from their children [6].

"Families are the main context of learning for most people. Learning within the family is usually more lasting and influential than any other. Family life provides a foundation and context for all learning' [20].

Mackenzie [12] states that family learning is about normal family activities that involve at least one adult and one child in an action that creates learning. For example, enjoying book, taking a walk, visiting the Post Office, baking a cake, fixing a bicycle puncture or playing a computer games, all provide a context for family learning (p. 7). The National Family Learning Network UK defines family learning as being 'about families enjoying learning together', that includes member of the family (parents, carers and children) learning together, parents or carers learning separately with children or other family members, and children learning separately to share learning with other family members [12]. In the same paper, Mackenzie argues that 'family learning involves families enjoying learning together' (p. 9).

Elsewhere [24] we have chosen to discuss four dimensions of family learning of this kind drawn from the literature: (1) its non-didactive nature, (2) the levels of social collaboration, (3) the extent to which it is embedded in meaningful activity, and (4) how it is initiated by learner's interest or choice. We have also turned to social cognitive theory. Social learning theorists like Bandura ([1],[2]) contend that, to promote effective modelling, a role model must make sure that four essential conditions exist; attention, retention, motor reproduction, and motivation. That is, vicarious learning through familial role-modelling concerns learning through observing the actions of others in the family, and its effectiveness depends upon how well such people are able to support the learning of others.

Support from 'trusted others' is important, not least because such trustees are able to share concerns about their own lack of confidence and how common it is to have difficulties in certain areas. In this study, the research was conducted within a very sociable, non-didactic setting, where multi-age family groups chose to participate in meaningful activities. Within this, and adapted from Bandura's [2] work, we have sought to identify examples of: 
Level 1 actions: Where one of the family group initiates a task and acts as a role model. He or she gains the attention of the others as they watch the task unfold Level 2 action: Where the other member of the family then begin tasks of their own, guided by the better, more accomplished, more experienced members of group

Level 3 action: Where the 'learner' members of the family gain achievement in their tasks supported by, but largely independent of, their family role models Indications of Level 4 action: that the learners will try to take what they have learn from the setting and repeat, adapt and improve on what they have been doing.

In this way, Bandura [3], for example, states that the learning process begins with the learner modeling the experiences of other people in the particular social setting. This develops into the learner copying, or emulating the others, adults and other siblings, and then on to a self-controlled level [5].

\section{Play and play-learning}

In our work, we have added the additional component of play to learning [24]. As Kerr \& Apter [15] argue, while play is usually associated with children, and despite all of the differences between adults and children, play is still a suitable and respectable way to promote intense and meaningful adult-child learning. In this paper we explore the learning that happens when young and old are at play, what it means to be playful and just why this is 'fun'. In our view, play - and the enjoyment of play - is context dependent, so that some contexts invite and provide opportunities for play while, in others, play is restricted, disapproved of, curtailed or forbidden. To illustrate the former, a deliberately constructed 'play-zone', we draw our examples from museum education where the goal is 'edutainment' through hands-on activities designed both to elicit learning and enjoyment through play.

In this form of family play-learning, then, we emphasise make-and-play activities suited to intergenerational learning, where family groupings influence and learn from each other. In this research, our interest lies in activities with traditional Thai toys and, to do this, we delineate some aspects of play that drive the directions we take.

1. Play is a process

Play is experiential. Anything can become the object or the topic of play. While some objects invite play, it is not the object itself, but what is done with it that marks out play. In this study the 'props' of play are home-made paper caterpillars, a 'coconut mouse' and some wickerwork animals.

2. Play is personal

Play is personally directed, a disposition, mood, and undertaken for its own rewards. While it certainly has a social dimension, evident in the examples we give later, it is the individual who has the veto on play - a group cannot force an individual to play against his or her will. In our case, these volunteers came with a disposition to be playful (Kanhadilok and Watts, in press).

\section{Play is free choice}

This follows from 2 above: if the requirement to play is increased, or if external pressure is intensified, if the 'pleasure principle' diminishes, then play will cease - it becomes something else. It becomes a requirement, a chore, it is no longer play. In this study, participants were fully able to stop the task, leave the activities, and the 'play-zone' area at any point. None did.

4. Play entails risk

Play entails low risk in some instances, high risk in others. There may be no reward, simply the thrill of play. There is an invitation to risk in all games, physical risk (walking along the top of a wall, swinging high on a tyre over a river), of social risk (appearing foolish playing charades) of financial risk (in losing a game of poker).

5. Play is context-dependent

There are, in our view, 'play-zones and 'no-playzones. A given activity may be fun when done voluntarily and a similar activity may not be fun when done in a formal educational setting that awards grades. One can signal an end to play by leaving the play-frame. The informal voluntary setting here provided a positive context for play.

A learning environment is a space where the resources, time, and rationales for learning are available to a group of people to nurture, support, and value their learning of a proscribed range of information and ideas. As Reiber [18] points out, learning environments can be social places even when only one person can be found there. The centre of a learning environment is sharp, clear, and focused, but the edges are fuzzy. There are limits to each learning environment, both in what can be learned there and whose learning will be supported most. It is most common to describe a learning environment by the types of resources to be found there, but while the resources are crucial to a learning environment's effectiveness, resources are only as good as the conditions under which one has access to them. In figure 1 below we set out some of our broad framework, in this instance a model for 'learning play' to happen. 


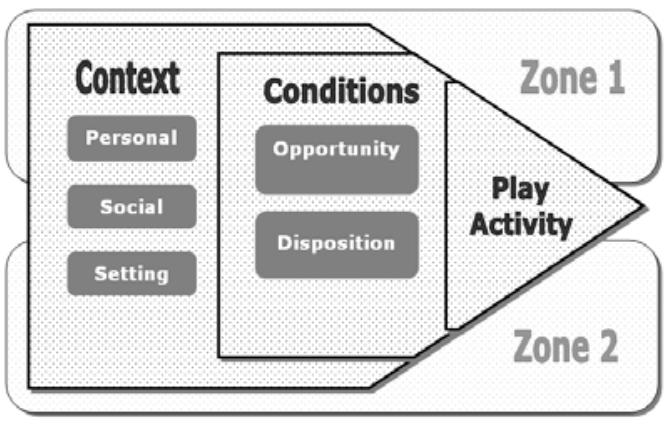

Figure 1. Two zones of play

The two zones represent those environments where play is - and is not - deemed appropriate. Zone 1 is a play zone, and is intended to encompass all of those physical, and virtual, spaces where play can commonly take place, including sporting arenas, parkland, areas of the countryside like woodlands and beaches, youth centres, arcades, playgrounds, theme parks, a comedy show, streets, gardens, bedrooms, game-worlds etcetera. Zone 2 is intended to represent the opposite, a no-play zone, those spaces where play is deemed a distraction, inappropriate, is uninvited, curtailed: a three-lane motorway, a church, a busy construction site, the company board-room, some lecture theatres, classrooms, a funeral, and so on. It is clear even in that distinction there are occasions where some play may be possible, especially where this contravenes conventions, conformity, and causes amusement. Even when the zone is appropriate, where the people and the setting are right, play may still not take place. As Else [22] maintains, play is personally directed, trades upon a disposition, a momentary mood and is undertaken for its own rewards. Play must involve pleasure: where there is no pleasure, no fun, no enjoyment, then there is no play. When play becomes tedious, is imposed or required, then it ceases to be play. When the fun ends, players become disillusioned, frustrated, bored - one can signal an end to play by leaving the play-setting. Moreover, play entails on opportunity for risk - low risk in some settings, high risk in others, for example, walking along the top of a wall, swinging high on a tyre over a river, of appearing foolish playing the game of charades.

\section{Traditional toys activity (TTTA) at the National Science Museum, Thailand}

As noted above, toys are the props of play. They are the objects or equipment with which individuals children and adults - will play for both enjoyment and knowledge, cognitive and imaginative [16]. Ovravec [13] defines toys as objects of interest, 'learning instruments' that stimulate social and intellectual imagination. They can challenge the player's abilities, respond to natural curiosity [16].
The classical example is Froebel's 'gifts', sets of toys used for children's development [8]. Most toys stimulate individuals' play but there are particular interactive toys that promote the richest play [16]. For example, hands-on playthings are seen to be more fascinating for visitors (children, teenagers and adults) in a museum because they can handle and practice many skills, they are interesting and enjoyable [11]. Given its role as a science museum, its purpose is to emphasise scientific knowledge and it aims, in general, to provide a ratio of $75 \%$ scientific knowledge and 25\% local Thai wisdom [21]. Local wisdom is introduced in parallel to western modern science, so that activities explore related part of local wisdom with these toys.

The Thai Traditional Technology gallery is one of six themes in the Science Museum at the National Science Museum, Thailand, in this case designed specifically to inspire learning about the relationship between scientific knowledge and local Thai wisdom [21]. One section of this gallery is the collection of the old traditional toys where the traditional Thai toys activity occurs. The TTTA is a 'play-zone' (Zone 1) in the science museum and the traditional toys are the props of play. They are the objects or equipment with which individuals - children and adults - play for both enjoyment and knowledge, cognitive and imaginative [16]. In this case, traditional Thai toys are used to stimulate learning, knowledge, imagination, construction, and encourage awareness of values [24]. For example, research shows [11] that hands-on playthings like these are seen to be more interesting and enjoyable because they can be handled, and participants can practice skills.

Traditional Thai toys are made from local or waste materials that adults and children use to make for play. Playing with traditional Thai toys reflects local wisdom, ways of life and the cultures of the community. Learning science through traditional Thai toys aims to encourage learners to seek both scientific knowledge and this local wisdom. Nearnchalearm [25] points out that playing with traditional Thai toys helps children to develop both learning process and science process skills, for example, measuring, observing, predicting, making decision and inferring. He argues that learning science from such cultural tradition promotes attitudes toward science that make the link between these two forms of knowledge and understanding.

TTTA has been developed under a constructivist theory of learning [17], which focuses on understanding. Constructivism is a model of how learning takes place and implies that adults and children are always active agents in the process of meaningful learning. Children learn not by receiving transmitted knowledge, but by interpreting experiences and information against schemas of prior knowledge. For example, activity-based or hands-on 
learning allows for meaningful 'grappling with the concepts under study' [28]. Traditional Thai toy activities also allow participants to experience pleasure by learning-through-doing in making and playing with the toys. Learning-by-doing at the TTTA uses toys based on elementary scientific principle which closely simulate real-life scenarios, give enough scope for innovation, challenge and make learning science playful and exciting [24].

Thus, TTTA aims to encourage people who participate the activity to learn scientific knowledge parallel local wisdom through making and playing with the traditional Thai toys playfully. This aim follows the mission of the organisation that is to develop 'edutainment' learning resources in science and technology for people. Also, TTTA was designed for playfulness of people, through enjoyable making the toys by themselves and acquiring playfulness from playing the toys with their friends or family, parallel learning science and local wisdom. We draw on three examples in this study: two handicraft toys, the 'paper caterpillar' and the 'coconut mouse', and one wickerwork toy, called the 'flying bird'.

\section{Research method}

\subsection{The science museum}

The research was conducted at the study area in the traditional technology gallery at the Science Museum in the National Science Museum, Thailand. The traditional Thai toys activity is designed for general visitors who visit this gallery and are interested in participating in the traditional technology hands-on activity. The activity begins with an introduction of the activity, the exhibition and collections of the old toys and then explains the details of the toys: information about the toys, a general outline of how to make the toys. Then participants are allowed free access to make and play with the toys and discuss what and how they learn from this activity.

\subsection{Sample}

The sample in this study are family groups that voluntarily participate with the TTTA, contain children of at least 10 years or over. Fifty-five families participated, and these included 125 children, teenagers and adults. All family members were asked to complete the Toy Learning Outcomes Questionnaire (TLOQ) to explore the learning outcomes from the activity.

\subsection{Toy Learning outcomes questionnaire}

The Toy Learning Outcomes Questionnaire is adapted from the Generic Learning Outcomes questionnaire used with school students at workshops in a museum [7]. The questionnaires uses a four-point a Likert-style rating scale [4] to generate numerical data. The range of answers used here were:

1 = Nothing, $2=$ Little, $3=$ Some and $4=$ A lot.

The original is English version then was translated to Thai and then re-translated to English again to ensure the validity. TLOQ, after omitting irrelevant items from the original survey and adding a relevant scale, consisted of 33 items in relation to seven areas of interest: Knowledge and understanding (4 items), Skills (5 items), Attitude and values (5 items), Enjoyment, inspiration and creativity (4 items), Action, behaviour and progression (5 items), Science learning (6 items) and Attitude towards Thai local wisdom (4 items). The final section of this questionnaire was designed to explore participants' comment about the activity with the open-end questions.

\section{Results}

\subsection{Toy learning outcomes questionnaire}

Mean and standard deviation of TLOQ scales are presented in the table 1 . The full sample of 125 people completed the questionnaires. Overall, the mean range was between 3.2420 (Knowledge and understanding) and 3.4900 (Attitude toward Thai wisdom), representing responses between 'Some' and 'A lot'.

Table 1. Average results of all areas of toy learning outcomes

\begin{tabular}{|c|c|c|c|}
\hline Learning outcomes & $\mathrm{N}$ & Mean & $\begin{array}{c}\text { Std. } \\
\text { Deviation }\end{array}$ \\
\hline $\begin{array}{l}\text { 1.Knowledge and } \\
\text { understanding }\end{array}$ & 125 & 3.2420 & .43060 \\
\hline 2.Skills & 125 & 3.4064 & .44209 \\
\hline 3.Attitude and values & 125 & 3.3840 & .39152 \\
\hline $\begin{array}{l}\text { 4.Enjoyment, inspiration } \\
\text { and creativity }\end{array}$ & 125 & 3.4020 & .45448 \\
\hline $\begin{array}{l}\text { 5. Action, behaviour and } \\
\text { progression }\end{array}$ & 125 & 3.3904 & .42033 \\
\hline 6. Science learning & 125 & 3.4080 & .40850 \\
\hline $\begin{array}{l}\text { 7. Attitude toward Thai } \\
\text { wisdom }\end{array}$ & 125 & 3.4900 & .42288 \\
\hline $\begin{array}{l}\text { Total Toy learning } \\
\text { outcomes }\end{array}$ & 125 & 3.3890 & .33257 \\
\hline Valid N (list wise) & 125 & & \\
\hline
\end{tabular}


These are positive results and participants seem to have gained learning outcomes from TTTA. The strongest responses were towards 'Attitude toward Thai wisdom' (3.490), and 'Science learning' (3.4080). The others ('Skills', 'Enjoyment, inspiration and creativity', 'Action, behaviour and progression', 'Attitude and values') are almost similar, the mean between 3.384-3.4064. The weakest responses were towards 'Knowledge and understanding' (3.2420). These results indicate that families gained learning outcomes from the TTTA. They appear to have learned most in relation to both 'local Thai wisdom' and 'scientific knowledge' when compared with others. This is largely consistent with the purpose of the study. The TTTA is rare to find in schools or other places, so participants can learn new knowledge about traditional Thai toys, culture and local wisdom from the TTTA. They also learned science from this activity through playing and making the toys. The results also indicate that they can develop skills, action, behaviour and progress from this activity and TTTA stimulates knowledge, understanding, attitudes, values, enjoyment, inspiration and creativity of the family.

\subsection{Perceptions derived from the open-ended questions}

The open-ended questions were answered by a large number of respondents. Most of children in this study wrote only short sentence in the space provided on the questionnaire, but adults presented significant comments. We summarise four main themes as following:

7.2.1. Knowledge, understanding, creativity and science. In general, adults asked that science museum provide more activities like this for children to learn, and some suggested that this kind of activity should find its way into the school curriculum. They gained scientific knowledge and felt they could adapt this activity to their daily lives, to encourage creative and cognitive thinking of their children:

"I like this activity very much because it can make children enjoy, gain more knowledge and understanding."

"I have never seen this activity before and I gained more new knowledge myself."

"This is a good activity. I will bring this knowledge to teach my children at home."

"This a good activity that can allow children to make the toys by themselves. This activity should continue".

7.2.2. Enjoyment and inspiration. The families also enjoy the activity. They were happy to make and play with the toys together:
" I like this activity because I can make new toys every time that I join the activity.”

"I appreciate this activity. This activity make us endure to make the toys and they are funny."

"I want to visit NSM again because I enjoy making and touching the toys. I like caterpillar paper toy."

7.2.3. Attitudes, values and Thai local wisdom. Participants learned about local wisdom include Thai culture, traditional Thai toys from the TTTA. They preferred to conserve local wisdom because examples are increasingly rare to find at present. Example of their comments are:

"I gained knowledge about Thai local wisdom and traditional Thai toys, and also, I can conserve Thai local wisdom"

"This activity makes children learn about the toys in the past that rare to find in present."

"This activity should to continue because it can encourage children to remember the materials, the toys and how to make the toys. It also conserves making the traditional Thai toys.”

7.2.4. Family play-learning. This activity provided opportunities for family learning through play. Families can learn the TTTA through intergeneration learning. They said:

"This is a good activity for family that can bring all people in the family, children and adults to join activity together that can make better understanding in the family."

"This activity is suitable for providing knowledge and playfulness and encourages relationship in the family."

\section{Summary discussion}

The Traditional Thai Toy Activities discussed in this study provide families with an opportunity for learning through make-and-play activities in an informal learning context. To a greater or lesser extent, these activities have stimulated knowledge, understanding, attitudes, values, enjoyment, inspiration and creativity of 125 family participants. The TTTA encouraged participants to learn 'standard' Western science, about issues for example within physics, biology and environmental science. They have also provided insights into local Thai wisdom, and an awareness of the value of traditional local Thai wisdom for people. The knowledge within these family groups has grown through individuals' direct experience of making and playing with toys. Essentially, they have also learned from each other, through the kinds of levels and activities described by Bandura [3]. The environmental context has enabled their play-learning, which has been supported by other exhibitions in the science museum such as the collection of the traditional Thai 
toy, from the written resources to hand and from the museum's 'explainers'.

While we are eager to show that these kinds of activities are strong and worthwhile learning experiences for families, we are also keen to observe the processes by which family learning happens. This continues to be an area of rich research as we map the ebb and flow of knowledge and understanding between different generations within these family groups.

\section{References}

[1] A. Bandura, Social Foundations of Thought and action. New york: Prentice Hall, 1986.

[2] A. Bandura, "Social Cognitive Theory of Mass Communication”, Media Psychology, 3, 2001, pp. 265299.

[3] A. Bandura, The Evolution of Social Cognitive Theory. In K.G> Smith \& M.A. Hitt (Eds.) Great Minds in Management. Oxford: Oxford University, 2005.

[4] A.N. Oppenheim, Questionnaire design, Interviewing and attitude measurement. New edition. New York: Continuum, 2001.

[5] B. Zimmerman, and D. Schunk, Self-Regulated Learning and Academic Achievement. (2nd edition), Mahwah,NJ, Lawrence Erlbaum Associates, Inc, 2001.

[6] D.M. Watts, "The PLUS factors of Family Science". International Journal of Science Education, 23 (1), 2001, pp. 83-96.

[7] E. Hooper-Greenhill, "Measuring Learning in Museums: the Research and Its Findings". Journal of Education in Museums, 28:36, 2007, pp. 8.

[8] F.L. Wright, and B. Fuller, The legendary Froebel Gifts. Available at: http://www. Froebelgifts.com/gift (accessed 16 January 2011).

[9] G. Black, The Engaging Museum: Developing Museums for Visitor Involvement. New York: Routledge. 2005.

[10] J. Cooper, “ Is that silly women still following us? Researching informal family visits to the Natural History Museum”. Journal of Education in Museums, 18: 1997, pp. 17-18.

[11] J. Goolnik, and N. Curtis, "Hands on". Journal of Education in Museums, 16, 1995, pp. 215.

[12] J. Mackenzie, Family learning engaging with parents. UK: Dunedin Academic Press Ltd, 2010.

[13] J .A. Ovravec, "Interactive Toys and Children's Education”. Childhood Education, 77, 2000, pp. 13 - 19.

[14] J.H. Falk, and L.D. Dierking, Learning from Museum.USA: AltaMira a Press, 2000.
[15] J. H. Kerr, \& M. J. (Eds.), Apter, Adult play: A reversal theory approach. Rockland, MA: Swets \& Zeitlinger, 1991.

[16] J.K. Frobose, Learning Through Play-a Child's job. USA: Colorado State University press, 2008.

[17] K. S. Taber, and D.M. Watts, "Constructivism and concept learning in chemistry - perspectives from a case study”. Research in Education, 58, 1997, pp. 10-20.

[18] L.P. Rieber, Designing learning environments that excite serious play. Paper presented at the annual meeting of the Australasian Society for Computers in Learning in Tertiary Education, Melbourne, Australia, December, 2001.

[19] M. Borun, M. Chambers, and A. Cleghorn, "Families are Learning in Science Museums”. Curator, 33 (2): 1996, pp.123-138.

[20] National Institute of Adult Continuing Education (NIACE), Rich beyond price: making the most of family. NIACE Family Learning Matters, Topic Paper No 3, Leicester: NIACE, 1995.

[21] National Science Museum, Thailand, Traditional Technology. Pathumthani, Thailand: National Science Museum press, 2007.

[22] P. Else, The value of play. London: Continuum International Publishing, 2009.

[23] P. Kanhadilok, Family play-learning through informal education: Play and make activities with traditional Thai toys activity at a science museum, Thesis, Brunel University, London, 2012.

[24] P. Kanhadilok, and D.M. Watts, "Western science and local Thai wisdom: using museum toys to develop bignosis. the Canadian Journal of Science Mathematics and Technology Education, November, 2012.

[25] P. Nearnchalearm, "Learning Science through Local toys”. Wichakarn Journal.8 (4), 2005, pp. 17-24.

[26] M. Fenichel and H.A. Schweingruber, Surrounding by Science: Learning Science in Informal Environments. Washington,D.C.: The National Academies Press. 2010.

[27] R. Wood, "Museum learning: A family focus". Journal of Educational in Museum, 1990, pp. 20.

[28] Wm. W. Cobern, "Constructivism and Non-Western Science Education Research". International Journal of Science Education, 4(3), 1996, pp. 287-302. 